\title{
Genetic differentiation in populations of Drosophila melanogaster from the Peoples' Republic of China: comparison with patterns on other continents
}

\author{
Chengshan Jiang \\ John B. Gibson and \\ Huazhong Chen*
}

\author{
Population Genetics Group, \\ Research School of Biological Sciences, \\ The Australian National University, P.O. Box 475, \\ Canberra City, ACT. 2601, Australia.
}

Geographic variation at eight allozyme loci in eight natural populations of Drosophila melanogaster from the People's Republic of China (P.R.C.) was collated with data from Japanese populations and compared with previous reports for other continents. $G 6 p d^{F}, E s t-6^{1.00}$ and $A d h^{S}$ were significantly correlated with latitude. Whilst the variation in Est$6^{1.00}$ was opposite to that previously reported, $A d h^{S}$ showed latitudinal clines consistent with data from the northern and southern hemispheres. A thermostable variant, $A d h^{F C h D}$, was found at high frequency in the southern P.R.C. populations and it is suggested that the mutation occurred in this region and was then dispersed to other continents.

\section{INTRODUCTION}

Extensive surveys of allozyme variation in natural populations of the cosmopolitan species Drosophila melanogaster have shown that some polymorphic loci e.g., alcohol dehydrogenase (Adh) and esterase-6 (Est-6) vary latitudinally, whereas others e.g., phosphoglucomutase (Pgm) are relatively homogenous across zoogeographic zones (Singh, Hickey and David, 1982; Oakeshott et al., $1983 \mathrm{~b}$ and references therein; Singh and Rhomberg, 1987). The latitudinal variation in some polymorphisms has been shown to be consistent between continents both in the northern and southern hemispheres, whenever direct comparisons have been made (Johnson and Schaffer, 1973; Vigue and Johnson, 1973; Wilks et al., 1980; David, 1982; Oakeshott, et al., 1981, 1982, $1983 a, b)$, although major gaps remain for a worldwide data set as few data are available for South America and Asia. This latitudinal differentiation, which is not explained by the frequency of inversions (Voelker et al., 1978, Knibb, 1983), has been claimed as evidence for natural selection imposed by latitudinally varying environmental factor(s). Consistent latitudinal differentiation on continents in both hemispheres bolsters this argument,

\footnotetext{
* Institute of Genetics, Fudan University, Shanghai, Peoples' Republic of China.
}

although for each locus it remains possible that the focus of selection is on phenotypes controlled by gene(s) in ubiquitous disequilibria with the enzyme locus.

In Australian populations Adh, Acph (acid phosphatase), Gpdh (sn-glycerol-3-phosphate dehydrogenase), Odh (octanol dehydrogenase), G6pd (Glucose-6-phosphase dehydrogenase), Pgd (6-phospho-gluconate dehydrogenase) and Est-6 show significant latitudinal clines (Oakeshott et al., 1981, 1982, 1983a, b) which are similar in sign to those found in the eastern region of North America (Johnson and Schaffer, 1973). D. melanogaster populations occur in Australia from $10^{\circ}$ to $45^{\circ} \mathrm{S}$ which are similar to the latitudes of the People's Republic of China (P.R.C.) $\left(20^{\circ}\right.$ to $55^{\circ} \mathrm{N}$ ). In order to test the generality of the latitudinal differentiation found in Australia we have scored allozyme frequencies at eight polymorphic loci in $D$. melanogaster populations from eastern P.R.C. and collated the data with recent observations on Japanese populations.

\section{MATERIALS AND METHODS}

Adult D. melanogaster were collected at eight sites in the eastern region of the Peoples' Republic of China (P.R.C.) over a latitudinal range of $20^{\circ} \mathrm{N}$ (fig. 1). The populations, which were all large, were 


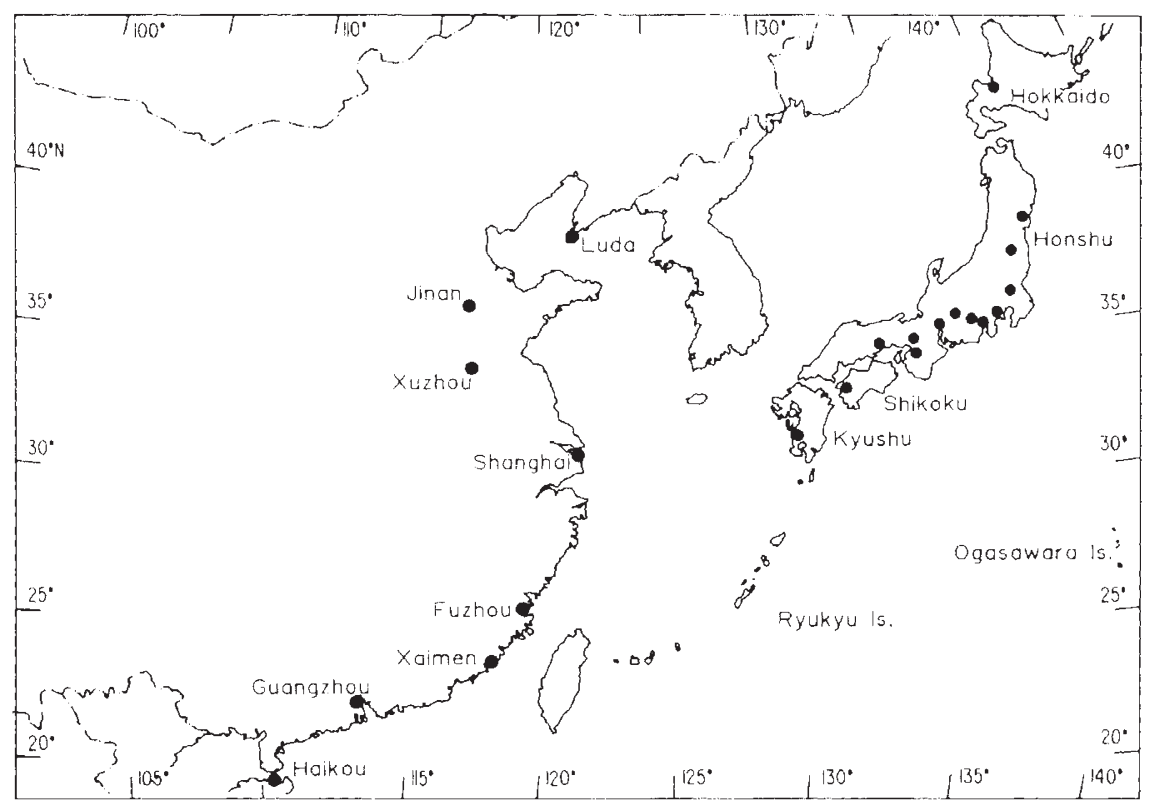

Figure 1 The location of the eight P.R.C. populations. Also shown are the locations of the eighteen Japanese populations (Watada et al., 1986) which comprise one sample from Hokkaida, eleven samples from Honshu, one sample from Shikoku, one sample from Kyushu, three samples from Ryukyu and one sample from Ogasawara.

sampled in the autumn of 1986 and air freighted to Canberra where at least 100 single female lines were established from each population and maintained by mass transfer at $20 \pm 1^{\circ} \mathrm{C}$ on our standard culture medium (Gibson and Wilks, 1988).

The P.R.C. samples were scored within three months of collection for variation at eight loci (Adh, Gpdh, Est-6, G6pd, Pgm, Odh, Acph, Pgd) after electrophoresis of single fly homogenates and staining on cellulose acetate membranes using published protocols (see Oakeshott et al., 1981, $1982,1983 a, b)$. For EST-6, the $p \mathrm{H}$ of the running buffer was increased to $p \mathrm{H} 8.5$ in order to best resolve electrophoretic variation ( $P$. Cooke, personal communication). Variation at the Est-6, $P g m, O d h$ and Acph loci was scored on the same single fly extracts.

The samples were also scored for alleles encoding heat resistant $\mathrm{ADH}$ using the techniques described by Wilks et al., (1980). A number of thermostability and heat sensitive $A d h$ alleles were extracted using $\mathrm{CyO}$ as a second chromosome balancer (Lindsley and Grell, 1967) and maintained as homozygotes. ADH activity levels in crude extracts of homozygotes using ethanol or 2-propanol as substrates, were assayed at $25^{\circ} \mathrm{C}$ or $40^{\circ} \mathrm{C}$ as previously described (Wilks et al., 1980).
Data for latitude, longitude and the 30 year averages of average daily maximum temperature in ${ }^{\circ} \mathrm{C}$ for the hottest $\left(T_{\max }\right)$ and the coldest $\left(T_{\min }\right)$ calender month, total rainfall in $\mathrm{mm}$ for the wettest $\left(R_{\max }\right)$ and driest $\left(R_{\min }\right)$ calender month for each site were obtained from Zhang and Lin (1985) and Sheng (1986). The altitudes of the collecting sites were all below 100 metres. Recently collected data on allele frequencies at some of the loci were available for eighteen populations in Japan (Watada, Tobari and Ohba, 1986) and these data for sites on each of the six islands (fig. 1) were collated with the present results for the P.R.C.

\section{RESULTS}

Allele frequencies at the eight loci scored in the eight P.R.C. populations are given in table 1.

At four loci-Pgm, Odh, Acph and Pgd-very little geographic variation in allele frequencies was observed, with the most common alleles always greater than $0 \cdot 9$. None of the alleles at these loci showed any significant variation with latitude or longitude. $G p d h$ was polymorphic in each of the populations but the frequency of $G p d h^{F}$ was not significantly correlated with latitude or longitude, either in the P.R.C. samples or in the collated data 
Table 1 Allele frequencies in the eight P.R.C. populations. The number of genes scored for each locus is shown in parenthesis at each site and the latitude of the site is indicated

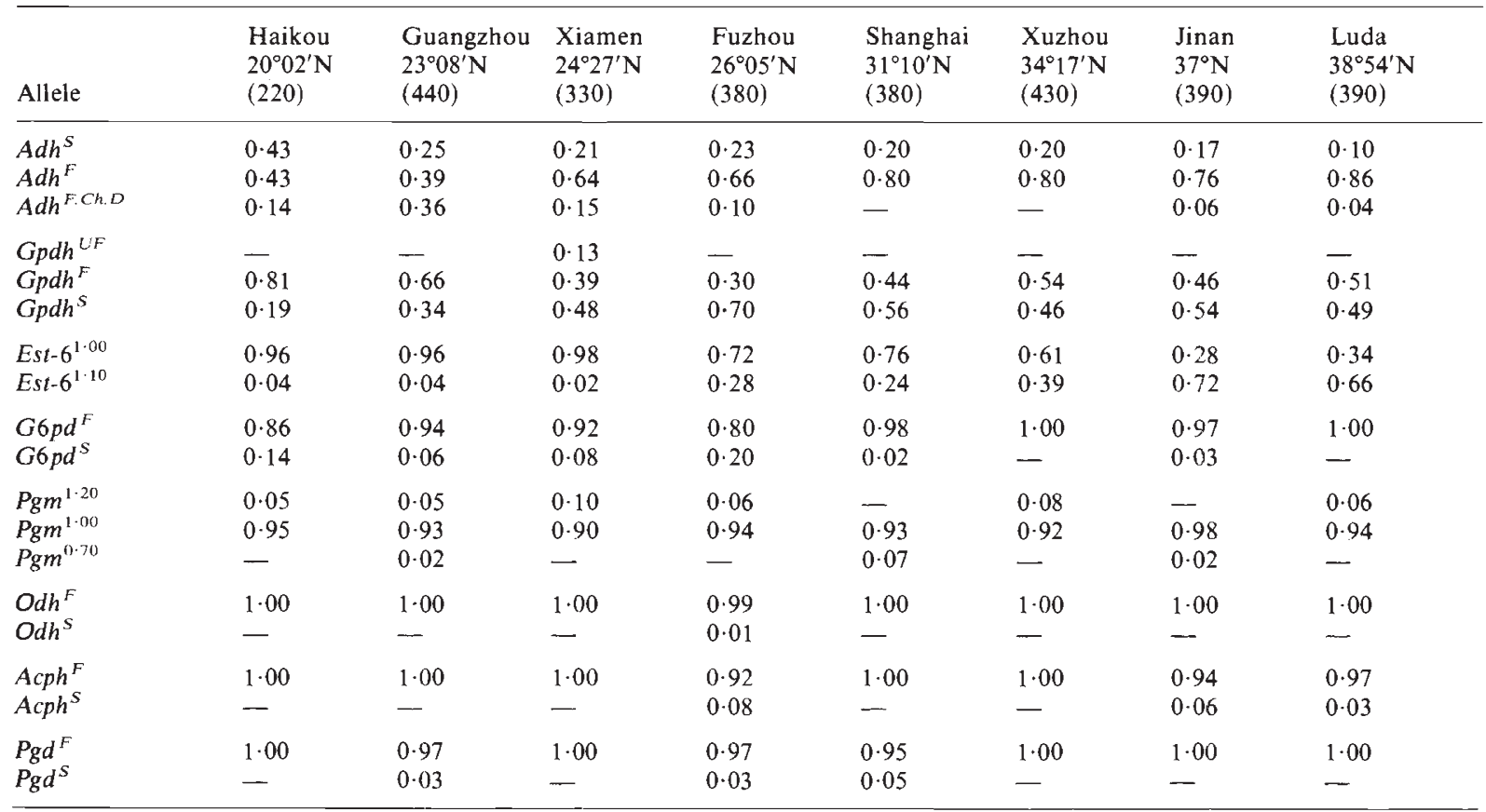

set. One population, Xiamen, had a relatively high frequency of $G p d h^{U F}$, which has only been found in previous surveys as a rare allele. G6pd was polymorphic in six populations, with the commonest allele, $G 6 p d^{F}$, significantly correlated with distance from the equator in the partial correlation (and also in the total data set) but not in the multiple regression coefficient (table 2).

The Est-6 and Adh loci were polymorphic in each population sampled and the variation was

Table 2 Partial correlation $(r)$ and multiple regression coefficients $(b)$ of angularly transformed allele frequencies on latitude and longitude in (a) the P.R.C. samples and (b) including data for Japanese populations

\begin{tabular}{|c|c|c|c|c|c|}
\hline & & \multicolumn{2}{|l|}{$r$} & \multicolumn{2}{|l|}{$b$} \\
\hline & & lat & long & lat & long \\
\hline$A d h^{S}$ & $\begin{array}{l}\text { (a) } \\
\text { (b) }\end{array}$ & $\begin{array}{l}-0.72^{*} \\
-0.64^{*}\end{array}$ & $\begin{array}{l}-0.50 \\
+0.53^{*}\end{array}$ & $\begin{array}{l}-0.62^{*} \\
-0.70^{*}\end{array}$ & $\begin{array}{r}-0.34 \\
0.54^{*}\end{array}$ \\
\hline Est $-6^{1 \cdot 00}$ & $\begin{array}{l}\text { (a) } \\
\text { (b) }\end{array}$ & $\begin{array}{l}-0.94^{* *} \\
-0.49^{*}\end{array}$ & $\begin{array}{l}0.52 \\
0.3\end{array}$ & $\begin{array}{l}-1.06^{*} \\
-0.55\end{array}$ & $\begin{array}{l}0 \cdot 23 \\
0 \cdot 31\end{array}$ \\
\hline$G 6 p d^{F}$ & $\begin{array}{l}\text { (a) } \\
\text { (b) }\end{array}$ & $\begin{array}{l}0.65^{*} \\
0.19\end{array}$ & $\begin{array}{l}-0.06 \\
-0.23\end{array}$ & $\begin{array}{l}0.73 \\
0.22\end{array}$ & $\begin{array}{r}0.48 \\
-0.26\end{array}$ \\
\hline
\end{tabular}

$* P<0.05$.

** $P<0.01$. also significantly correlated with latitude both in the P.R.C. samples and in the collated data (table 2). Est $-6^{1.00}$ decreased in frequency with increasing distance from the equator, but this was opposite in direction to the differentiation previously reported in the northern hemisphere (Johnson and Schaffer, 1973). At the $\boldsymbol{A} d \boldsymbol{d h}$ locus the variation was consistent with previous studies in showing that $A d h^{S}$ decreases in frequency with increasing latitude (Vigue and Johnson, 1973; Wilks et al., 1980). A surprising feature of the $A d h$ data was the high frequency (up to 36 per cent) of heat resistant $A d h$ alleles in the southernmost P.R.C. populations (similar results have been obtained in other samples from this region by $\mathrm{L}$. Chai, personal communication). The frequencies of heat resistant $A d h$ alleles were not significantly correlated with latitude in either the partial correlation $(r=-0.45$, $P>0.05)$ or the multiple regression $(b=0.44, P>$ $0.05)$.

To test whether these thermostability ADH variants encode enzyme with similar properties to ADH-FChD (which is equivalent to ADH-Fr and ADH-71 K, Gibson, et al., 1980) samples of heat resistant and heat sensitive alleles from three of the P.R.C. populations were extracted using $\mathrm{CyO}$ as a second chromosome balancer and made homozygous. Results of ADH assays on extracts 
Table 3 Comparison of ADH activities (standard errors in parenthesis) and thermostabilities in extracts derived from heat sensitive and heat resistant alleles extracted from the P.R.C. populations

\begin{tabular}{|c|c|c|c|}
\hline Origin of allele & $\begin{array}{l}\text { ADH activity } \\
\text { with propanol }\end{array}$ & $\begin{array}{l}\text { Activity } \\
\text { ratio* }\end{array}$ & $\begin{array}{l}\text { ADH activity remaining in } 40^{\circ} \mathrm{C} \\
\text { heat-treated extracts (per cent) }\end{array}$ \\
\hline \multicolumn{4}{|l|}{ Heat-resistant alleles } \\
\hline Control ADH-FChD ${ }^{(a)}$ & $131 \cdot 3(1 \cdot 8)$ & $4 \cdot 2$ & $94 \cdot 6$ \\
\hline Guangzhou & $130 \cdot 0(2 \cdot 0)$ & $4 \cdot 2$ & $95 \cdot 8$ \\
\hline Guangzhou & $103 \cdot 5(1 \cdot 2)$ & $4 \cdot 0$ & $81 \cdot 2$ \\
\hline Fuzhou & $190 \cdot 5(1.5)$ & $4 \cdot 9$ & 80.7 \\
\hline Jinan & $107 \cdot 5(5 \cdot 5)$ & $4 \cdot 5$ & $100 \cdot 0$ \\
\hline \multicolumn{4}{|l|}{ Heat-sensitive alleles } \\
\hline Control ADH-F $F^{(a)}$ & $195 \cdot 1(6 \cdot 0)$ & $6 \cdot 8$ & $59 \cdot 7$ \\
\hline Guangzhou & $197 \cdot 0$ (small) & $7 \cdot 3$ & $55 \cdot 1$ \\
\hline Fuzhou & $210 \cdot 1($ small $)$ & $6 \cdot 7$ & $51 \cdot 8$ \\
\hline Jinan & $209 \cdot 5(0.5)$ & $5 \cdot 2$ & $53 \cdot 6$ \\
\hline
\end{tabular}

* Ratio of activity with 2-propanol to activity with ethanol as substrate. (a) alleles described in Gibson et al., 1980.

of these homozygotes (table 3 ), using ethanol and 2-propanol as substrates showed that the activity ratios and heat stabilities of the ADH encoded by the thermostability alleles were very similar to those previously shown to be characteristic of ADH-FChD but different to the control ADH-F (Gibson et al., 1980). A heat sensitive $A d h^{F}$ allele extracted from Jinan differed in activity ratio both from the ADH-F and ADH-FChD controls $(P<$ $0.01)$ and this variant is being investigated further.

In the data from the eight P.R.C. populations, there was no significant linkage disequilibria between allozymes scored on the same fly (Est-6, $P g m, O d h$ and $A c p h$ ) and none of the allele frequencies at any locus were significantly correlated with any of the climatic variables, after the latitudinal variation had been taken into account (data not shown).

\section{DISCUSSION}

The landmasses of the Peoples' Republic of China and Australia span similar latitudes but lie in different hemispheres, so that $D$. melanogaster sampled from the two areas provides tests of the generality of latitudinal differentiation of specific polymorphic loci. Previous surveys, mainly of populations in Australiasia, Europe and North America, have shown that five loci-Adh, Odh, G6pd, Pgd and Est-6-exhibit latitudinal variation although the degree of association can vary between continents. In the present study, the first to sample populations in mainland China, three of these loci, Adh, G6pd and Est-6, show latitudinal variation but that for Est-6 is opposite in sign to elsewhere in the northern hemisphere and that for $G 6 p d$ is only significant in the partial correlation.

Previous surveys (Oakeshott et al., 1983a,b) have shown significant differences in mean $O d h^{s}$ and $P g d^{F}$ frequencies between populations at similar latitudes on different continents, with a low level of polymorphism at the Pgd locus. In the P.R.C. and Japanese data the highest frequency of $O d h^{S}$ is 0.23 but in most populations it is less than 0.05. Similarly, $P g d$ is monomorphic in most of the populations we describe although at similar latitudes on other continents some populations are polymorphic at this locus.

The inconsistent result for Est-6, compared to earlier surveys, is most surprising as this locus is polymorphic in most populations. The electrophoresis conditions we used were chosen because they maximised the discrimination of EST-6 phenotypes (Cooke et al., 1987) and we used their control alleles in our experiments. Thus any imprecise resolution of EST-6 phenotypes is less likely to have occurred in our study (P. Cooke, personal communication). It is possible that the variation in Est $-6^{1.00}$ in the P.R.C. populations is due to linkage disequilibrium with $\operatorname{In}(3 L) P$, which has breakpoints either side of the locus and which decreases in frequency with increasing latitude in North America (Voelker et al., 1977) and in Australia and Europe (Knibb, Oakeshott and Gibson, 1982). Cytological investigations of the P.R.C. and Japanese material will test this possibility. It is also relevant to the inconsistency of the variation that Est $-6^{1 \cdot 00}$ frequencies do not change in the direction expected when populations are transplanted and reared in different latitudes (Oakeshott et al., 1988). 
The data for $G 6 p d$ are consistent with those from other continents in showing a relatively shallow latitudinal cline. The variation in the present data was not related to any of the climatic variables and again this mirrored earlier results which showed that there were no consistent climatic relationships in data from different continents.

The latitudinal differentiation in $A d h^{S}$ in the P.R.C. populations is consistent in form with that found in Australia which in 1986 samples was unchanged from that found in the studies carried out in 1978, (J. B. Gibson and C. Jiang, unpublished data and see Anderson et al., 1987), and with that first reported in North America (Johnson and Schaffer, 1977). In general $\boldsymbol{A d h ^ { S }}$ frequencies are lower in the P.R.C. populations than at comparable latitudes in Australia but otherwise the latitudinal differentiation is similar. In contrast to the earlier surveys in which $A d h^{S}$ was consistently related to Tmax (Oakeshott et al., 1982) the relationship, although positive, is non-significant in this data set and in the data reported by Anderson et al. (1987). In the eastern region of North America there is evidence that the latitudinal variation in $A d h^{S}$ is now less marked (Gail Simmons, personal communication) and in the western region of the continent the relationship between $A d h^{F}$ and latitude, although positive, is weak and non-significant (Smith et al., 1984).

An unexpected feature of the P.R.C. Adh data is the high frequency of a thermostable variant which shares characteristics with ADH-FChD. Similar $A d h$ variants have previously been found in surveys of natural populations in North America (Sampsell 1977, Smith et al., 1984) and Australia (Wilks et al., 1980; Gibson, Wilks and Chambers, $1981,1982)$ at frequencies as high as 0.16 in one population but generally with average values closer to 0.04 . The frequency of $A d h^{F C h D}$ tends to be highest at intermediate frequencies of $A d h^{F}$, i.e., in the mid region of the cline. The surveys also show that populations in regions of Australia and North America with climates similar to that of southern China do not have frequencies of $A d h^{F C h D}$ above $0 \cdot 03$. Heat resistant $A d h^{F}$ alleles have also been found at low frequency (less than 1 per cent) in the Canary Islands (Hernandez et al., 1986) but not in central African populations (J. David, personal communication). It is relevant that $A d h^{F}$ is relatively rare in tropical Africa (David, 1982) where, on the basis of biogeographical and phylogenetic evidence, it is believed D. melanogaster originated (Lemeunier et al., 1985).
The evolutionary history of $D$. melanogaster and the worldwide distribution of $A d h^{F C h D}$ (which probably arose from a mutation in $A d h^{F}$, Chambers et al., 1981, Gibson, Wilks and Chambers, 1981, Collet, 1988) prompts the speculation that the $A d h^{F C h D}$ mutation occurred in southern China from where it was then dispersed. It is relevant that $D$. melanogaster was not found in Papua New Guinea before the 1970s, despite serious collecting attempts (Bock, 1980), and so it is possible the species only became established in Australia with European settlement. Similarly the evidence of museum collections shows that $D$. melanogaster became established in North America in the second half of the nineteenth century (L. Throckmorton, personal communication).

If North America and Australia were colonised relatively recently by $D$. melanogaster then the latitudinal variation in $A d h^{s}$ (and to a lesser extent $G 6 p d^{F}$ ) on these continents has developed over the past century in contrast to mainland China where $D$. melanogaster is likely to have been endemic for much longer. Singh and Rhomberg (1987) have discussed two selective and two nonselective mechanisms which could give rise to latitudinal variation. For example allele frequencies might be tracking latitudinally varying environmental factors or there may be gene flow between two distinct latitudinally separate selective regimes. The non-selective causes include the intermixing of differentiated populations and gradients in allele frequencies deriving from changes in seasonal cycles along a latitudinal gradient. The consistancy of the $A d h^{S}$ latitudinal cline, at least in eastern Australia and eastern China, coupled with the evidence that transplanted populations change in $A d h$ frequency towards the recipient area (Oakeshott et al., 1988), is strongly suggestive of some kind of balancing selection focussed on phenotypes to which variation in the $A d h$ region of the genome makes a significant contribution.

Acknowledgements We thank Ann Wilks, Anh Cao and Peter Cooke for help with the electrophoresis techniques and Professor C. C. Tan for assistance in collecting samples. C. J. acknowledges the financial support of the State Education Commission of the People's Republic of China and an Australian National University Postgraduate Scholarship.

\section{REFERENCES}

ANDERSON, P. R, KNIBB, W. R. AND OAKESHOTT, J. G. 1987. Observations on the extent and temporal stability of latitudinal clines for alcohol dehydrogenase allozymes and for chromosome inversions in Drosophila melanogaster. Genetics, 75, 81-88. 
BOCK, I. R. 1980. Current status of the Drosophila melanogaster species-group (Diptera). Syst. Entomol., 5, 341-356.

CHAMBERS, G. K., LAVER, W. G., CAMPBELL, S. AND GlBSON. J. B. 1981. Structural analysis of an electrophoretically cryptic alcohol dehydrogenase variant from an Australian population of Drosophila melanogaster. Proc. Natl. Acad. Sci. USA, 78, 3103-3107.

COLLET. C. 1988. Recent origin for a thermostable alcohol dehydrogenase allele of D. melanogaster. J. Mol. Evol., 27, 142-146.

COOKE, P. H., RICHMOND, R. C. AND OAKESHOTT, J. G. 1987. High resolution electrophoretic variation at the esterase-6 locus in a natural population of Drosophila melanogaster. Heredity, 59, 259-264.

DAVID, J. R. 1982. Latitudinal variability of Drosophila melanogaster. Allozyme frequencies divergence between European and Afrotropical populations. Biochem. Genet., $20,747-761$.

GIBSON, I. B., CHAMBERS, G. K., WILKS, A. V. AND OAKESHOTT, J. G. 1980. An electrophoretically cryptic alcohol dehydrogenase variant in Drosophila melanogaster. I. Activity ratios, thermostability, genetic localisation and comparison with two other thermostable variants. Aust. J. Biol. Sci., 33, 479-489.

GIBSON, J. B.. Wilks, A. V. AND CHAMBERS, G. K. 1981. Population variation in functional properties of alcohol dehydrogenase. In Gibson, J. B. and Oakeshott, J. G. (eds) Genetic Studies of Drosophila Populations, Australian National University Press, Canberra.

GIBSON, I. B., WILKS, A. V. AND CHAMBERS. G. K. 1982. Genetic variation at the alcohol dehydrogenase locus in Drosophila melanogaster: A third ubiquitous allele. Experientia, 38 , 653-654.

GIBSON, 1. B. AND WILKS, A. V. 1988. The alcohol dehydrogenase polymorphism of Drosophila melanogaster in relation to environmental ethanol, ethanol tolerance and alcohol dehydrogenase activity. Heredity, 60, 403-414.

HERNÁNDEZ, M., PADRÓN, G. AND CABRERA, V. M. 1986. Persistance of an alcohol dehydrogenase thermostable variant in a natural population of Drosophila melanogaster. Genet. Res. Camb., 47, 143-146.

JOHNSON. F. M. AND SCHAFFER, J. F. 1973. Isozyme variability in species of the genus Drosophila. VII. Genotype-environment relationships in populations of $D$. melanogaster from the eastern United States. Biochem. Genet., 10, 149-163.

KNIBB, W. R. 1983. Chromosome inversion polymorphisms in Drosophila melanogaster. III. Gametic disequilibria and the contributions of the inversion clines to the ADH and GPDH allozyme clines in Australasia. Genetics, 61, 139. 146.

KNIBR, W. R., OAKESHOIT, J. G. AND GIBSON, J. B. 1981. Chromosome inversion polymorphism in Drosophila melanogaster. 1. Latitudinal clines and associations between inversions in Australasian populations. Genetics, 98, 833-847.

LEMEUNIER, F, DAVID. J. R., TSACAS, L. AND ASHBURNER, M. 1985. The Drosophila melanogaster species group. In Ashburner, M., Carson, H. L. and Thompson, J. M. (eds) The Genetics and Biology of Drosophila, Academic Press, London.
I.INDSLEY, D. L. AND GRELL, E. H. 1968. Genetic variations of Drosophila melanogaster. Carn. Inst. Wash. Pub., Number 627.

OAKESHOTT, J. G., WILSON, S. R. AND KNIBB, W. R. 1988. Selection affecting enzyme polymorphism in enclosed Drosophila populations in a natural environment. Proc. Nat. Acad. Sci. USA, 85, 293-297.

OAKESHOTT, J. G., CHAMBERS, G. K., GIBSON, J. B. AND WILL COCKS, D. A. 1981. Latitudinal relationships of Esterase-6 and phosphoglucomutase gene frequencies in Drosophila melanogaster. Heredity, 47, 385-396.

OAKESHOTT, J. G., GIBSON, J. B., ANDERSON, P. R., KNIBB, W. R., ANDERSON. D. G. AND CHAMBERS, G. K. 1982. Alcohol dehydrogenase and glycerol-3-phosphate dehydrogenase clines in Drosophila melanogaster on different continents. Evolution, 36, 86-96.

OAKESHOTT, J. G., CHAMBERS, G. K., GIBSON, J. B., EANES, W. F. AND W1LLCOCKS, D. A. $1983 a$. Geographic variation in G6pd and $P g d$ allele frequencies in Drosophila melanogaster. Heredity, 50, 67-72.

OAKESHOTT, J. G., GIBSON, J. B., WILLCOCKS, D. A. AND CHAMBERS, G. K. 1983 b. Latitudinal variation in octanol dehydrogenase and acid phosphatase allele frequencies in Drosophila melanogaster. Theor. Appl. Genet., 65, 191-196.

SAMPSELL, B. 1977. Isolation and genetic characterization of alcohol dehydrogenase thermostability variants occurring in natural populations of Drosophila melanogaster. Biochem. Genet., 15, 971-988.

SHENG, C. 1986. General Principles of Climate in China. Science Press, Beijing (in Chinese).

SINGH, R. S., HICKEY, D. A. AND DAVID, J. 1982. Genetic differentiation between geographically distant populations of Drosophila melanogaster. Genetics, 101, 235-256.

SINGH. R. S. AND RHOMBERG, L. R. 1987. A comprehensive study of genic variation in natural populations of Drosophila melanogaster. II. Estimates of heterozygosity and patterns of geographic differentiation. Genetics, 117, 255-272.

SMITH, M. R., CHAMBERS, G. K., BROOKS, L. D., COHAN, F. M. AND COHAN, S. C. 1984. How many Adh clines on the west coast of North America? Dros. Inf. Serv., 60, 188-189.

VIGUE, C. L. AND JOHNSON, F. M. 1973. Isozyme variability in species of the genus Drosophila. VI. Frequencyproperty-environment relationships of allelic alcohol dehydrogenases in D. melanogaster. Biochem. Genet., 9, 213-227.

VOELKER, R. A., COCKERHAM, C. C., JOHNSON, F. M., SCHAFFER, H. E., MUKAI, T. AND METTLER, L. E. 1978. Inversions fail to account for allozyme clines. Genetica, 88, 515-527.

WATADA, M., TOBARI, Y. N. AND OHBA, S. 1986. Genetic differentiation in Japanese populations of Drosophila simulans and D. melanogaster. I. Allozyme polymorphisms. Jpn. J. Genet., 61, 253-269.

WILKS, A. V.. GIBSON, J. B., OAKESHOTT, J. G. AND CHAMBERS, G. K. 1980. An electrophoretically cryptic alcohol dehydrogenase variant in Drosophila melanogaster: II. Postelectrophoresis heat-treatment screening of natural populations. Aust. J. Biol. Sci., 33, 575-585.

ZHANG, J. AND LIN, Z. 1985. Climate in China. Shanghai Science and Technology Press (in Chinese). 